\title{
Salt excretion in normotensive individuals with metabolic syndrome: a population-based study
}

\author{
Sérgio Lamego Rodrigues, Marcelo Perim Baldo, Roberto de Sá Cunha, Rodrigo Varejão Andreão, \\ Maria del Carmen Bisi Molina, Christine Pereira Gonçalves, Eduardo Miranda Dantas and José Geraldo Mill
}

The objective of this study was to investigate the association between sodium intake and metabolic syndrome (MS) in individuals free from the confounding effects of increased blood pressure (BP). In all, a total of 1655 individuals (45.8\% men) who participated in the MONICA-WHO/Vitoria Project, mean age $45 \pm 11$ years were investigated. According to NCEP-ATP III criteria, MS prevalence was 32.9 and $85 \%$ of these individuals had BP $>130 / 85 \mathrm{~mm} \mathrm{Hg}$. Thus, high BP represents the main MS risk factor. Twelve-hour nocturnal urine (1900 to 0700 hours) was used to measure urinary sodium and potassium excretion. Sodium excretion was associated with BP. From the optimal BP level up to stage III hypertension, the mean (median) sodium excretion increased from 99 (89) to $128(134) \mathrm{mEq}$ and from $81(69)$ to $112(103) \mathrm{mEq}$ in men and women, respectively $(P<0.001$ for trend; median). However, when 781 individuals with $\mathrm{BP}<130 / 85 \mathrm{~mm} \mathrm{Hg}$ (including 80 drug-free normotensive individuals with MS) were stratified according to the gender and number of MS components, no significant differences were observed either in the urinary volume or in the sodium or potassium excretion. For each of the four MS components, sodium excretion was $96 \pm 48,97 \pm 53,108 \pm 65$ and $97 \pm 49 \mathrm{mEq}$ for men, and $83 \pm 51,83 \pm 58,80 \pm 49$ and $93 \pm 45 \mathrm{mEq}$ for women, respectively. No differences were found in urinary sodium excretion in normotensive individuals, regardless of the presence of MS. Therefore, it seems that high sodium intake is not an MS predictor per se as suggested earlier. Hypertension Research (2009) 32, 906-910; doi:10.1038/hr.2009.122; published online 21 August 2009

Keywords: body mass index; metabolic syndrome; salt intake; urinary sodium

\section{INTRODUCTION}

Metabolic syndrome (MS) represents multiple interrelated cardiovascular disease risk factors. ${ }^{1}$ Elevated blood pressure (BP) is one risk component deemed useful in identifying individuals with MS, regardless of the diagnostic criteria used. ${ }^{2}$ High BP is one of the most prevalent risk factors and the single greatest contributor to cardiovascular disease worldwide. ${ }^{3}$ Recent studies have reported that BP increases cardiovascular risk even at pre-hypertensive levels. ${ }^{4}$ Moreover, it has been suggested that an increase in sodium intake facilitates the development of MS. ${ }^{5}$ However, observational studies have shown a positive association between sodium intake and BP, within and between populations. ${ }^{6}$ Furthermore, there is evidence that lowering the salt intake reduces $\mathrm{BP}$, prevents hypertension ${ }^{7}$ and attenuates cardiovascular disease risk. ${ }^{8}$ Therefore, considering that hypertension is the most common risk factor associated with the diagnosis of MS, we sought to study individuals with MS, free from the confounding effects of increased BP. Thus, the aim of this study was to investigate the association between urinary sodium excretion, a measure of dietary sodium intake, and all other variables that cluster to determine MS development. In particular, this relationship was investigated in the subsample of 80 drug-free, normotensive $(\mathrm{BP}<135 / 85 \mathrm{~mm} \mathrm{Hg})$ individuals with MS.

\section{METHODS}

Study design and population

We performed a cross-sectional, population-based study to determine the prevalence and severity of cardiovascular risk factors among the urban population of Vitória, Brazil (1999-2001). Data were collected according to the general guidelines of the MONICA-WHO Project. ${ }^{9}$ A total of 1662 individuals (25-64 years) were selected from the eligible population. These individuals came to the University Hospital to undergo clinical and laboratory exams. The design and sampling of this survey are described elsewhere. ${ }^{10}$ The project was approved by the institutional ethics committee and all participants gave informed written consent.

\section{Procedures}

Blood pressure was measured in fasting individuals during the morning period (0700 to 0900 hours) while patients were in the sitting position by using a standard mercury sphygmomanometer on the left arm after a 5-10 min rest period. The first and fifth phases of Korotkoff sounds were used to indicate systolic and diastolic BP, respectively. Mean values of systolic and diastolic BP were calculated from two measurements carried out by two independent trained staff members, with a minimal interval of $10 \mathrm{~min}$ between the two readings. BP was defined according to The Sixth Joint National Committee on Prevention, Detection, Evaluation, and Treatment of High BP. ${ }^{11}$ Participants were considered hypertensive in the presence of systolic BP $\geqslant 140 \mathrm{~mm} \mathrm{Hg}$ or 
diastolic BP $\geqslant 90 \mathrm{~mm} \mathrm{Hg}$ or if they used antihypertensive drugs, including diuretics. For biochemical analysis, blood samples were collected soon after BP measurements to determine glucose, triglycerides, total cholesterol and highdensity lipoprotein-cholesterol lipoprotein by using validated commercial analytical kits.

Anthropometric parameters were obtained by trained technicians using standard methods. Body weight was taken on a calibrated scale to the nearest $0.1 \mathrm{~kg}$. Height was taken with a wall-mounted stadiometer to the nearest $0.5 \mathrm{~cm}$. Body mass index (BMI) was calculated as body weight $(\mathrm{kg})$ to the squared height $\left(\mathrm{m}^{2}\right)$. Waist circumference (WC) was measured in the mean point between the lowest rib margin and iliac crest with the participant standing and at the maximum point of normal expiration.

Nocturnal urine was collected for a 12-h period (1900 to 0700 hours) during the night preceding the clinic visit. Sodium and potassium concentrations in urine were measured using calibrated electrode-selective devices. The daily sodium intake was estimated on the basis that $45 \%$ of the total daily sodium excretion in urine occurs during the night period (1900 to 0700 hours). This parameter was validated in an earlier study with 50 normotensive individuals. ${ }^{10}$

According to ATP III criteria, ${ }^{12}$ MS was defined when any three of the five following diagnostic criteria were present: WC $>102 \mathrm{~cm}$ in men and $>88 \mathrm{~cm}$ in women; type II DM or fasting glucose $\geqslant 110 \mathrm{mg}$ per $100 \mathrm{ml}$; high-density lipoprotein-cholesterol $<40 \mathrm{mg}$ per $100 \mathrm{ml}$ in men and $<50 \mathrm{mg}$ per $100 \mathrm{ml}$ in women; triglycerides $\geqslant 150 \mathrm{mg}$ per $100 \mathrm{ml}$; systolic $\mathrm{BP} \geqslant 130 \mathrm{~mm} \mathrm{Hg}$ and/or diastolic BP $\geqslant 85 \mathrm{~mm} \mathrm{Hg}$. Diabetes was defined when a positive history was present or the fasting blood glucose was $\geqslant 126 \mathrm{mg}$ per $100 \mathrm{ml}$.

\section{Statistical analysis}

Statistical analysis was carried out using the SPSS 13.0 statistical package (SPSS Inc., Chicago, IL, USA). Data are described as means \pm s.d. and medians for continuous variables. Proportions are used to express dichotomous variables. The goodness of fit for normal distribution was evaluated using the Kolmogorov-Smirnov test. To test for mean differences, Student's $t$-test or analysis of variance (with Tukey's post hoc test) was used. Multivariate linear stepwise regression and the Univariate General Linear Model were used to adjust for confounding factors. Kruskal-Wallis one-way analysis of variance was used for median comparisons. BMI, triglycerides and $12 \mathrm{~h}$ urinary sodium excretion were analyzed after log transformation. Statistical significance was set at $P<0.05$ for proportions and means, unless stated otherwise.

\section{RESULTS}

Seven individuals were removed from the analysis because of incomplete data to diagnose MS. Therefore, the data are reported for 1655 participants (759 men and 896 women). The prevalence of MS was $32.9 \%$ (251 men and 294 women, 46 and 54\%, respectively) and the prevalence of hypertension was $42 \%$ ( $51 \%$ in men). Eighty participants (38 men and 42 women) with MS had BP lower than $130 / 85 \mathrm{~mm} \mathrm{Hg}$ and were not using antihypertensive drugs.

General clinical characteristics of the total sample according to gender are shown in Table 1. All variables were higher in men, except age, fasting glucose and urine volume, which were similar in both genders, and BMI and high-density lipoprotein-cholesterol, which were lower in men than in women.

In relation to urinary sodium excretion according to BP classification, Figure 1 shows a steady rise as BP increases. From the optimal BP level to stage III hypertension, regardless of gender, the mean (median) unadjusted sodium excretion increased from 99 (89) to 128 (134) $\mathrm{mEq}$ and from 81 (69) to 112 (103) $\mathrm{mEq}$ in men and women, respectively $(P<0.001$ for trend; median). However, when the analysis was performed with urinary sodium corrected for body weight, urinary sodium still tended to increase from $1.38 \mathrm{mEq} / \mathrm{kg}$ in the normal BP group to $1.59 \mathrm{mEq} / \mathrm{kg}$ in the stage III hypertension individuals $(P=0.14$ for trend). Furthermore, when the model was adjusted for WC, the corrected sodium excretion increased from $1.37 \mathrm{mEq} / \mathrm{kg}$ in the normal BP group to $1.66 \mathrm{mEq} / \mathrm{kg}$ in the stage III hypertensive individuals $(P<0.001)$.

In addition, the relationship among urinary sodium excretion and BMI categories was investigated in individuals with MS. There was a positive and significant association with crude sodium values, which increased from $67 \pm 51 \mathrm{mEq}$ in the lowest BMI category to $118 \pm 62 \mathrm{mEq}$ in the obese group. However, when sodium corrected for weight was analyzed, a negative significant association was detected with values decreasing from $1.61 \pm 0.98 \mathrm{mEq} / \mathrm{kg}$ in the normal BMI class down to $1.35 \pm 0.74 \mathrm{mEq} / \mathrm{kg}$ in the obese group.

Furthermore, the whole sample was categorized as normotensive or hypertensive and gender stratified. Hypertensive individuals excreted more urinary sodium (mean \pm s.d.) compared with the normotensive group (men: $114 \pm 63$ and $100 \pm 54 \mathrm{mEq}$; women: $106 \pm 60$ and $86 \pm 54 \mathrm{mEq}$, respectively; $P<0.001$ ). When urinary sodium was corrected for body weight, a significant difference was still detected, with the hypertensive and normotensive individuals excreting 1.52 and $1.41 \mathrm{mEq} / \mathrm{kg}$, respectively $(P=0.007)$.

In addition, we explored the general characteristics of individuals with normal $\mathrm{BP}(<130 / 85 \mathrm{~mm} \mathrm{Hg})$ stratified according to the gender and number of MS components (300 men and 481 women). Data from 80 normotensive individuals (not using antihypertensive drugs)

Table 1 Baseline characteristics of the sample according to gender

\begin{tabular}{|c|c|c|c|c|}
\hline Variable & All subjects (1655) & Men (759) & Women (896) & $\mathrm{P}$-value \\
\hline Age (years) & $45 \pm 11(45)$ & $45 \pm 11(45)$ & $45 \pm 11(45)$ & 0.90 \\
\hline SBP (mm Hg) & $128 \pm 22(124)$ & $130 \pm 20(127)$ & $126 \pm 23(121)$ & $<0.001$ \\
\hline DBP (mm Hg) & $84 \pm 14(83)$ & $87 \pm 14(86$ & $82 \pm 14(80)$ & $<0.001$ \\
\hline BMI $\left(\mathrm{kg} \mathrm{m}^{-2}\right)$ & $26.2 \pm 5(26)$ & $25.8 \pm 4(25)$ & $26.5 \pm 5(26)$ & 0.003 \\
\hline Waist circumference $(\mathrm{cm})$ & $86 \pm 12(86)$ & $89 \pm 11(89)$ & $84 \pm 13(82)$ & $<0.001$ \\
\hline Triglycerides (mg per $100 \mathrm{ml}$ ) & $139 \pm 137(105)$ & $164 \pm 176(126)$ & $119 \pm 86(96)$ & $<0.001$ \\
\hline HDL-c (mg per $100 \mathrm{ml})$ & $45 \pm 12(44)$ & $42 \pm 12(40)$ & $48 \pm 12(46)$ & $<0.001$ \\
\hline Glucose (mg per 100 ml) & $105 \pm 31(98)$ & $105 \pm 28(100)$ & $104 \pm 34(97)$ & 0.39 \\
\hline $\mathrm{U}$ volume $12 \mathrm{~h}(\mathrm{I})$ & $0.85 \pm 0.45(0.75)$ & $0.85 \pm 0.48(0.71)$ & $0.86 \pm 0.43(0.79)$ & 0.56 \\
\hline Urine creatinine $12 \mathrm{~h}$ (mg) & $694 \pm 341(648)$ & $820 \pm 361(799)$ & $587 \pm 281(549)$ & $<0.001$ \\
\hline U. $\mathrm{Na}^{+} 12 \mathrm{~h}(\mathrm{mEq})$ & $99 \pm 58(88)$ & $107 \pm 59(99)$ & $93 \pm 57(82)$ & $<0.001$ \\
\hline U. $\mathrm{K}^{+} 12 \mathrm{~h}(\mathrm{mEq})$ & $24 \pm 17(20)$ & $25 \pm 18(21)$ & $22 \pm 16$ (19) & $<0.001$ \\
\hline $\mathrm{Na}^{+} / \mathrm{K}^{+}$ratio & $4.4 \pm 3.2(4.3)$ & $5.0 \pm 3.6(4.4)$ & $4.7 \pm 2.8(4.2)$ & 0.05 \\
\hline
\end{tabular}

Abbreviations: BMI, body mass index; DBP, diastolic blood pressure; HDL-c, high-density lipoprotein-cholesterol; $\mathrm{Na}^{+} / \mathrm{K}^{+}$, sodium/potassium ratio in $12-\mathrm{h}$ urine; $\mathrm{SBP}$, systolic blood pressure; Ur. $\mathrm{K}^{+} 12 \mathrm{~h}, 12-\mathrm{h}$ urinary potassium excretion; $\mathrm{Ur}_{\mathrm{N}} \mathrm{Na}^{+} 12 \mathrm{~h}, 12$ - $\mathrm{h}$ urinary sodium excretion; Ur. volume, urine volume $12 \mathrm{~h}$ Data are shown as mean \pm s.d. and (median). 


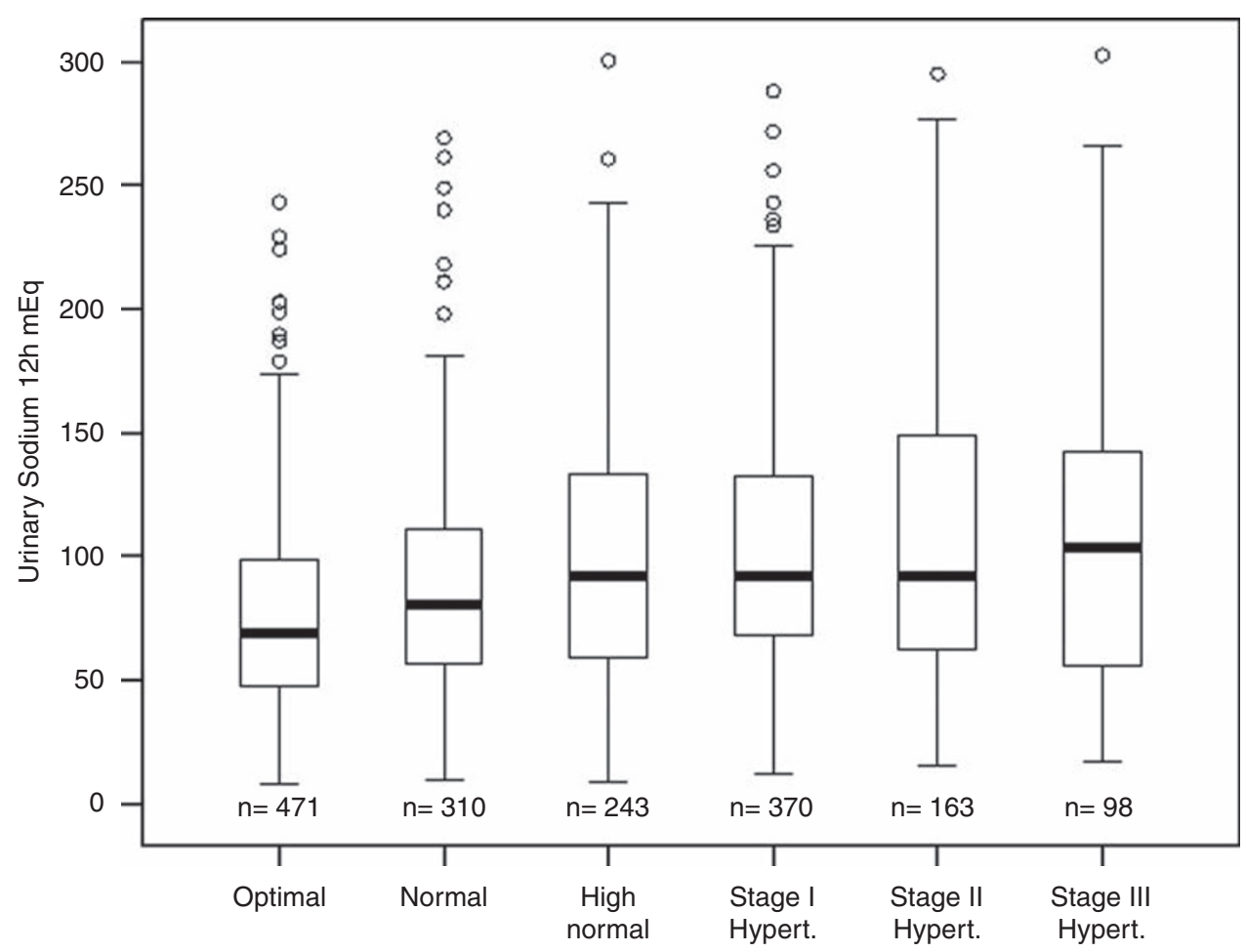

BP classification

Figure 1 Urinary sodium excretion according to blood pressure classification. Box plot of blood pressure (BP) classification according to the Sixth Report of the Joint National Committee on Prevention, Detection, Evaluation, and Treatment of High Blood Pressure. ${ }^{11}$ From the Kruskal-Wallis one-way analysis of variance for median comparison, $P$ for trend $<0.001$. $n=$ number of individuals in each BP group.

Table 2 Characteristics of individuals with normal blood pressure ( $<130 / 85 \mathrm{~mm} \mathrm{Hg}$ ) according to gender and number of metabolic syndrome components

\begin{tabular}{|c|c|c|c|c|c|}
\hline Number of MS components & 0 & 1 & 2 & 3 or 4 & $\mathrm{P}$-value \\
\hline Men (n) & 76 & 107 & 77 & 38 & \\
\hline Age (years) & $38 \pm 10(36)$ & $40 \pm 10$ (39) & $43 \pm 10(42)$ & $46 \pm 11(44)$ & 0.03 \\
\hline $\mathrm{SBP}(\mathrm{mm} \mathrm{Hg})$ & $112 \pm 9(112)$ & $114 \pm 9(115)$ & $114 \pm 8(114)$ & $116 \pm 8(117)$ & 0.19 \\
\hline BMI $\left(\mathrm{kg} \mathrm{m}^{-2}\right)$ & $22 \pm 2(22)$ & $23 \pm 3(23)$ & $25 \pm 3(25)$ & $26 \pm 4(25)$ & $<0.001$ \\
\hline U. volume $12 \mathrm{~h} \mathrm{(I)}$ & $0.78 \pm 0.5(0.6)$ & $0.78 \pm 0.5(0.6$ & $0.92 \pm 0.5(0.8)$ & $0.95 \pm 0.7(0.7)$ & 0.11 \\
\hline U. $\mathrm{Na}^{+} 12 \mathrm{~h}(\mathrm{mEq})$ & $96 \pm 48(90)$ & $97 \pm 53(93)$ & $108 \pm 65(101)$ & $97 \pm 49(91)$ & 0.49 \\
\hline U. $\mathrm{K}^{+} 12 \mathrm{~h}(\mathrm{mEq})$ & $23 \pm 15(19)$ & $23 \pm 12(20)$ & $28 \pm 31(22)$ & $29 \pm 12(26)$ & 0.17 \\
\hline $\mathrm{Na}^{+} / \mathrm{K}^{+}$ratio & $4.7 \pm 2(4.4)$ & $4.7 \pm 3(3.9)$ & $5.5 \pm 8(4.0)$ & $3.5 \pm 2(3.2)$ & 0.18 \\
\hline U. creatinine & $728 \pm 256(719)$ & $817 \pm 382(799)$ & $851 \pm 289(836)$ & $871 \pm 327(834)$ & 0.05 \\
\hline Women (n) & 90 & 225 & 124 & 42 & \\
\hline Age (years) & $40 \pm 10(39)$ & $40 \pm 9(40)$ & $42 \pm 9(43)$ & $46 \pm 10(46)$ & 0.03 \\
\hline $\mathrm{SBP}(\mathrm{mm} \mathrm{Hg})$ & $108 \pm 8(108)$ & $109 \pm 9$ (109) & $111 \pm 10(112)$ & $114 \pm 10(116)$ & 0.02 \\
\hline $\mathrm{BMI}\left(\mathrm{kg} \mathrm{m}^{-2}\right)$ & $22 \pm 3(22)$ & $24 \pm 4(23)$ & $26 \pm 5(25)$ & $30 \pm 6(29)$ & $<0.001$ \\
\hline U. volume $12 \mathrm{~h}(\mathrm{I})$ & $0.79 \pm 0.4(0.7)$ & $0.80 \pm 0.4(0.7)$ & $0.77 \pm 0.4(0.7)$ & $0.96 \pm 0.4(0.9)$ & 0.08 \\
\hline U. $\mathrm{Na}^{+} 12 \mathrm{~h}(\mathrm{mEq})$ & $83 \pm 51(79)$ & $83 \pm 58(70)$ & $80 \pm 49(67)$ & $93 \pm 45(92)$ & 0.63 \\
\hline U. $\mathrm{K}^{+} 12 \mathrm{~h}(\mathrm{mEq})$ & $21 \pm 15$ (19) & $22 \pm 19(18)$ & $20 \pm 12(17)$ & $23 \pm 11(20)$ & 0.87 \\
\hline $\mathrm{Na}^{+} / \mathrm{K}^{+}$ratio & $4.8 \pm 4(4.0)$ & $4.6 \pm 2(4.0)$ & $4.0 \pm 3(3.9)$ & $3.9 \pm 2(4.3)$ & 0.77 \\
\hline U. creatinine & $535 \pm 272$ (499) & $565 \pm 278(547)$ & $552 \pm 242(528)$ & $705 \pm 405(622)$ & 0.01 \\
\hline
\end{tabular}

Abbreviations: BMI, body mass index; $\mathrm{Na}^{+} / \mathrm{K}^{+}$, sodium/potassium ratio; SBP, systolic blood pressure; $\mathrm{U} . \mathrm{K}^{+} 12 \mathrm{~h}, 12-\mathrm{h}$ urinary potassium excretion; $\mathrm{U}$. $\mathrm{Na}^{+} 12 \mathrm{~h}, 12-\mathrm{h}$ urinary sodium excretion; U. volume, urine volume $12 \mathrm{~h}$.

Data are shown as mean \pm s.d. and (median).

with three and four MS components were combined in a single group and classified as having MS (Tables 2 and 3). No significant differences were observed in urinary volume, urinary sodium, potassium or sodium to potassium excretion ratio, independent of the number of MS components present concurrently in each group. All individuals with two or more MS components were older and heavier, whereas the 
Table 3 Characteristics of individuals with normal blood pressure $(<130 / 85 \mathrm{~mm} \mathrm{Hg}$ ) according to gender and presence of metabolic syndrome

\begin{tabular}{|c|c|c|c|}
\hline Variable & MS & No MS & P-value \\
\hline $\operatorname{Men}(n)$ & 38 & 261 & \\
\hline Age (years) & $46 \pm 11(43)$ & $40 \pm 10(40)$ & 0.006 \\
\hline Weight (kg) & $78.7 \pm 17(75)$ & $69.1 \pm 10(69)$ & $<0.001$ \\
\hline $\mathrm{BMI}\left(\mathrm{kg} \mathrm{m}^{-2}\right)$ & $26.4 \pm(26)$ & $23.9 \pm 3(24)$ & $<0.001$ \\
\hline Waist circumference $(\mathrm{cm})$ & $93 \pm 14(91)$ & $84 \pm 9(83)$ & $<0.001$ \\
\hline SBP (mm Hg) & $116 \pm 8(117)$ & $114 \pm 9(114)$ & 0.2 \\
\hline U. $\mathrm{Na}^{+} 12 \mathrm{~h}(\mathrm{mEq})$ & $97 \pm 49(91)$ & $100 \pm 51(94)$ & 0.75 \\
\hline $\mathrm{Na}^{+} / \mathrm{K}^{+}$ratio & $3.6 \pm 1.8(3)$ & $4.9 \pm 4.6(4)$ & 0.08 \\
\hline Women $(n)$ & 42 & 440 & \\
\hline Age (years) & $46 \pm 10(10)$ & $41 \pm 10(40)$ & $<0.001$ \\
\hline Weight (kg) & $74.6 \pm 15(70)$ & $60.3 \pm 12(58)$ & $<0.001$ \\
\hline $\mathrm{BMI}\left(\mathrm{kg} \mathrm{m}^{-2}\right)$ & $30.0 \pm 6(28)$ & $24.3 \pm 4(24)$ & $<0.001$ \\
\hline Waist circumference $(\mathrm{cm})$ & $92 \pm 11(93)$ & $78 \pm 11(75)$ & $<0.001$ \\
\hline $\mathrm{SBP}(\mathrm{mm} \mathrm{Hg})$ & $114 \pm 8(116)$ & $110 \pm 9(109)$ & 0.003 \\
\hline U. $\mathrm{Na}^{+} 12 \mathrm{~h}(\mathrm{mEq})$ & $93 \pm 44(92)$ & $82 \pm 54(78)$ & 0.22 \\
\hline $\mathrm{Na}^{+} / \mathrm{K}^{+}$ratio & $4.4 \pm 1.7(4)$ & $4.5 \pm 2.7(4)$ & 0.80 \\
\hline
\end{tabular}

Abbreviations: BMI, body mass index; $\mathrm{Na}^{+} / \mathrm{K}^{+}$, sodium/potassium ratio in $12-\mathrm{h}$ urine; $\mathrm{SBP}$ systolic blood pressure; U. Na $12 \mathrm{~h}, 12$-h urinary sodium excretion.

Data are shown as mean \pm s.d. and (median).

BP level was significantly higher only in women who had increased mean BMI compared with men $\left(30 \pm 6\right.$ and $26 \pm 5 \mathrm{~kg} \mathrm{~m}^{-2}$, respectively; $P<0.05)$. It is noted that 271 individuals were taking antihypertensive drugs and only 45 had BP lower than 130/85 mm Hg. Even when these individuals were excluded from analysis, to avoid bias, the urinary sodium excretion values did not show differences between groups, regardless of the gender and number of MS components (data not shown).

Prevalence of MS individual components according to gender is depicted in Figure 2, showing that BP higher than $130 / 85 \mathrm{~mm} \mathrm{Hg}$ was present in $\sim 85 \%$ of these individuals. Therefore, BP increase clearly represents the main risk factor for MS.

The characteristics of individuals with normal BP $(<130 /$ $85 \mathrm{~mm} \mathrm{Hg}$ ) according to the gender and presence of MS are summarized in Table 3. In both genders, as expected, age and anthropometric (obesity) measures were higher in the group with MS. However, urinary sodium and sodium to potassium excretion ratio did not differ between individuals with or without MS. Systolic BP levels were significantly higher only in women with MS.

In addition, we investigated whether there were differences in the excretion of urinary sodium corrected for body weight between individuals with and without MS. The mean \pm s.d. values were $1.27 \pm 0.64$ and $1.42 \pm 0.88 \mathrm{mEq} / \mathrm{kg}$, respectively; $P=0.06$.

\section{DISCUSSION}

Our main finding is that normotensive $(<130 / 85 \mathrm{~mm} \mathrm{Hg})$ individuals with MS who do not use antihypertensive drugs have similar $12 \mathrm{~h}$ urinary crude sodium excretion compared with normotensive individuals without MS, regardless of gender. Moreover, when urinary sodium corrected for weight was analyzed, MS individuals showed relatively lower sodium excretion (and presumably lower relative sodium intake), factors that might predispose them to remain normotensive.

Excessive sodium intake contributes to the development of hypertension. ${ }^{6,13}$ In our study, analyses of the whole sample showed a significant and steady increase in crude urinary sodium excretion in relation to increments in BP stages. This relationship was attenuated,

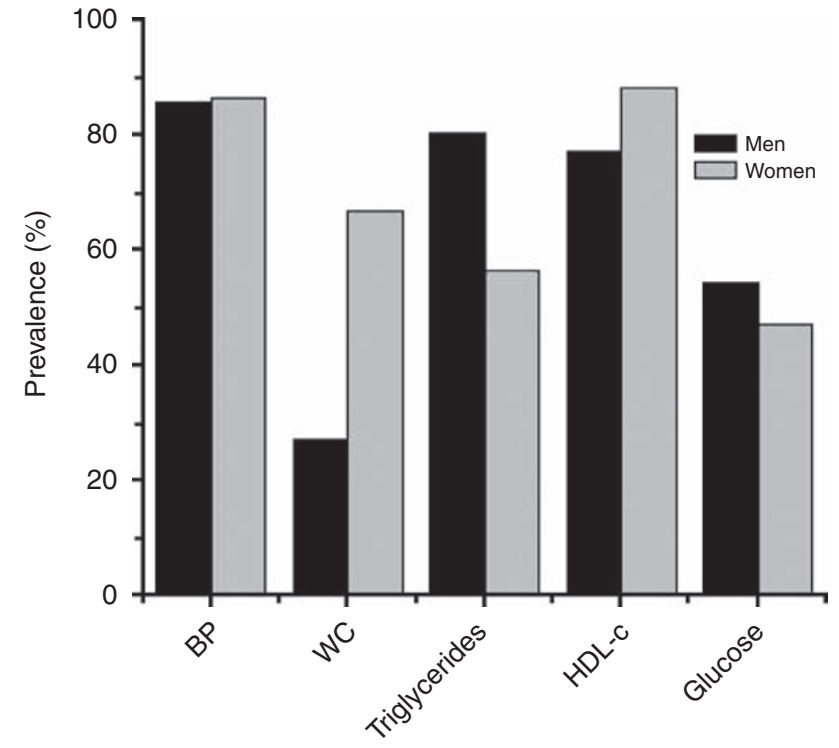

Figure 2 Prevalence of metabolic syndrome components according to gender in 545 individuals with metabolic syndrome. BP, blood pressure; WC, waist circumference.

but still with a trend to increase, when sodium was corrected for weight, and increased further when the model was adjusted for WC. In addition, according to BP categorization (normotensive/hypertensive), individuals with high BP showed significantly higher $12 \mathrm{~h}$ crude and weight-adjusted sodium excretion in comparison with normotensive individuals. Taken as a whole, our data show that the relationship of $\mathrm{BP}$ and sodium is independent of general adiposity (BMI or weight as surrogate). However, visceral adiposity (WC as surrogate) seems to be associated with higher sodium excretion, independent of body weight. Thus, our study shows a positive association between increased sodium excretion, abdominal adiposity and increased BP levels, in accordance with a recent report. ${ }^{14}$

Despite the positive association between salt intake and $\mathrm{BP}^{6,15}$ the relative contribution of sodium ingestion (measured as urinary sodium excretion) to BP variability in our population was very low $\left(r^{2}=0.02\right)$. When age and anthropometric variables (BMI and WC) were included in the stepwise multivariate analysis, the main BP determinants were WC, age, BMI and urinary sodium excretion, explaining $13,6,0.6$ and $0.5 \%$ of the variability, respectively. This low association between urinary sodium and BP seems to be a paradox at first glance. However, it could be explained by the overall high sodium intake found in our studied population. On the basis of an earlier report from our group, ${ }^{10}$ the estimated $24 \mathrm{~h}$ salt intake values for normotensive and hypertensive individuals were $11.9 \pm 7.0$ and $14.3 \pm 7.9 \mathrm{~g}$, respectively, which is more than twice the value recommended by the World Health Organization. ${ }^{16}$

Urinary sodium excretion was higher in men. However, the difference between genders disappeared when the values were corrected for weight (mean=1.45 and $1.47 \mathrm{mEq} / \mathrm{kg}$ for men and women, respectively, $P=0.40$ ), suggesting that the amount of ingested sodium (and presumably food) is body mass dependent and not gender dependent. Paradoxically, obese individuals (independent of MS) have lower relative sodium excretion, meaning that they probably eat relatively less salty food per kilogram compared with normal weight individuals. This finding might be secondary to the increased adipose tissue mass, which has a low metabolic demand. 
A recent report has suggested an association between increased sodium intake and the presence and severity of MS. ${ }^{5}$ In this study, 781 normotensive individuals ( $\mathrm{BP}<130 / 85 \mathrm{~mm} \mathrm{Hg}$ ) were investigated. No significant differences in urinary sodium, potassium or sodiumpotassium ratio excretion were identified, independent of the number of concurrent MS components. Furthermore, as expected, individuals with MS were older and heavier. However, BP was significantly higher only in women with MS. These women showed a 2.5 times higher prevalence of increased WC associated with increased BMI, showing clearly the positive association of BP levels with central fat accumulation.

Obesity is known to be associated with increased food and salt consumption. ${ }^{17-19}$ Indeed, it has been reported that high dietary sodium intake seems linked to increased consumption of sugarsweetened and soft drinks in children, which may in turn lead to weight gain and the development of obesity. ${ }^{20}$ The connection between obesity and hypertension is strongly established in the literature. In addition, it was also reported that central obesity is an independent predictor of increased salt-sensitive $\mathrm{BP}^{21}$ Insulin resistance has been suggested as the common link between different MS components. ${ }^{22}$ Thus, increased abdominal adiposity and other associated factors, such as increased leptinemia and reduced adiponectinemia, might have a substantial effect on renal sodium handling in individuals presenting with $\mathrm{MS},{ }^{23}$ predisposing women in our population to higher BP, even in a normotensive sample.

Inferences regarding MS per se in a population in which BP is the main diagnostic component for MS seem inappropriate. Accordingly, it was recently reported that MS in the absence of hypertension and diabetes was not associated with increased risk of all-cause or cardiovascular mortality. Moreover, among the five MS components, only the BP component predicted all-cause and cardiovascular mortality in men, whereas BP plus triglycerides and fast blood glucose were predictors only in women. ${ }^{24}$ Therefore, in light of the latest evidence, ${ }^{8}$ it seems that all individuals should be advised to undertake a more balanced and healthier diet pattern, emphasizing the need for salt reduction (independent of MS) and the importance of a healthy weight (particularly, a healthy waistline) and a more active lifestyle.

Therefore, our findings may have important implications for $\mathrm{BP}$ control in populations (such as the Brazilian population) in which hypertension is a dominant risk factor for cardiovascular disease, along with an increasing prevalence of obesity.

A possible weakness of our study is (as expected) the small number $(n=80)$ of normotensive, drug-free individuals with the diagnosis of MS. However, we further explored 781 individuals with $\mathrm{BP}<130$ / $85 \mathrm{~mm} \mathrm{Hg}$ and also found no significant differences in $12 \mathrm{~h}$ urinary crude or weight-adjusted sodium excretion, independent of the number of concurrent MS components analyzed.

Even though $24 \mathrm{~h}$ urine collection is the gold standard ${ }^{25}$ assessment for measuring salt intake, the difficulty in putting this measure into practice in population studies is well known. ${ }^{26}$ Our group has been using nocturnal urine collected for a 12 -h period as a biochemical marker of daily electrolyte intake. This parameter was validated in an earlier study with 50 normotensive individuals ${ }^{10}$ and it was recently replicated in 94 individuals of the general population (unpublished data).

In conclusion, in individuals without the confounding effects of increased BP $(<130 / 85 \mathrm{~mm} \mathrm{Hg})$, we did not find any differences in urinary crude or weight-adjusted sodium excretion, regardless of the presence of MS. Therefore, it seems that high sodium excretion is not a predictor of MS per se as suggested earlier. ${ }^{5}$ However, by increasing $\mathrm{BP}$ and presumably obesity, (mainly visceral, with its metabolic consequences), salt-rich diets may predispose individuals to MS, thus contributing to the high prevalence of MS in populations adopting the western lifestyle.

\section{ACKNOWLEDGEMENTS}

This study was supported by grants from Conselho Nacional de Desenvolvimento Científico e Tecnológico (CNPq, 304248/2005-3) and Fundação de Amparo a Pesquisa do Espírito Santo (FAPES, 35884886/2006).

1 Malik S, Wong ND, Franklin SS, Kamath TV, L'Italien GJ, Pio JR. Impact of the metabolic syndrome on mortality from coronary heart disease, cardiovascular disease and all causes in United States adults. Circulation 2004; 110: 1245-1250.

2 Reaven G. The metabolic syndrome: is this diagnosis necessary? Am J Clin Nutr 2006; 83: 1237-1247.

3 Ishizaka N, Ishizaka Y, Toda E, Hashimoto H, Nagai R, Yamakado M. Hypertension is the most common component of metabolic syndrome and the greatest contributor to carotid arteriosclerosis in apparently healthy Japanese individuals. Hypertens Res 2005; 28: 27-34.

4 Ezzati M, Lopez AD, Rodgers A, Vander Hoorn S, Murray CJ. Comparative Risk Assessment Collaborating Group. Selected major risk factors and global and regional burden of disease. Lancet 2002; 360: 1347-1360.

5 Hoffmann IS, Cubeddu LX. Salt and the metabolic syndrome. Nutr Metab Cardiovasc Dis 2009; 19: 123-128.

6 Stamler J. The INTERSALT Study: background, methods, findings, and implications. Am J Clin Nutr 1997; 65(suppl): 626S-642S.

7 Sacks FM, Svetkey LP, Vollmer WM, Appel LJ, Bray GA, Harsha D, Obarzanek E, Conlin PR, Miller III ER, Simons-Morton DG, Karanja N, Lin PH, the DASH-Sodium Collaborative Research Group. Effects on blood pressure of reduced dietary sodium and the dietary approaches to stop hypertension (DASH) diet. N Engl J Med 2001; 344: 3-10.

8 Cook NR, Cutler JA, Obarzanek E, Buring JE, Rexrode KM, Kumanyika SK, Appel LJ, Whelton PK. Long term effects of dietary sodium reduction on cardiovascular disease outcomes: observational follow-up of the trials of hypertension prevention (TOHP). Br Med J 2007; 334: 885-893.

9 Pereira A, Mota G, Cunha R, Herbenhoff F, Mill JG, Krieger J. Angiotensinogen 235T allele 'dosage' is associated with blood pressure phenotypes. Hypertension 2003; 41: 25-30.

10 Molina MCB, Cunha RS, Herkenhoff FL, Mill JG. Hypertension and salt intake in an urban population. Rev Saúde Pública 2003; 37: 743-750.

11 The Sixth Report of the Joint National Committee on Prevention, Detection, Evaluation, and Treatment of High Blood Pressure. Arch Intern Med 1997; 157: 2413-2446.

12 National Cholesterol Education Program. Executive summary of the Third Report of the National Cholesterol Education Program (NCEP) expert panel on Detection, Evaluation, and Treatment of High Blood Cholesterol in Adults (Adult Treatment Panel III). JAMA 2001; 285: 2486-2497.

13 Carvalho JMM, Baruzzi RJ, Howard PF. Blood pressure in four remote populations in the INTERSALT study. Hypertension 1989; 14: 238-246.

14 Mathiew P, Poirier P, Pibarot P, Lemieux I, Després JP. Visceral obesity. The link among inflammation, hypertension and cardiovascular disease. Hypertension 2009; 53: 577-584

15 Intersalt Cooperative Group. Intersalt: an international study of electrolyte excretion and blood pressure. Results for $24 \mathrm{~h}$ sodium and potassium excretion. Br Med J 1988; 297: 319-328.

16 AHA Dietary Guidelines revision. A statement for healthcare professionals from the Nutrition Committee of the American Heart Association 2000. Circulation 2000; 102 : 2284-2299.

17 Elliott P, Stamler J, Nichols R, Dyer AR, Stamler R, Kesteloot H, Marmot M. Intersalt Cooperative Research Group. Intersalt revisited: further analyses of $24 \mathrm{~h}$ sodium excretion and blood pressure within and across populations. Br Med J 1996; 312 : $1249 \mathrm{e} 53$.

18 Khaw K-T, Bingham S, Welch A, Luben R, O'Brien E, Warenham N, Day N. Blood pressure and urinary sodium in men and women: the Norfolk Cohort for the European Prospective Investigation into Cancer (EPIC-NORFOLK). Am J Clin Nutr 2004; 80: 1397e403.

19 Karppanen H, Mervaala E. Sodium intake and hypertension. Prog Cardiovasc Dis 2006; 49: $59 \mathrm{e} 75$.

20 He FJ, Marrero NM, Mac Gregor GA. Salt intake is related to soft drink consumption in children and adolescents: a link to obesity? Hypertension 2008; 51: 629e34.

21 Hoffmann IS, Cubeddu LX. Increased blood pressure reactivity to dietary salt in patients with the metabolic syndrome. J Hum Hypertens 2007; 21: 438-444.

22 Reaven GM. Banting Lecture 1988. Role of insulin resistance in human disease. Diabetes 1988; 37: 1595-1607.

23 Strazzullo P, Barbato A, Galletti F, Barba G, Siani A, lacone R, D’Elia L, Russo O, Versiero M, Farinaro E, Cappuccio FP. Abnormalities of renal sodium handling in the metabolic syndrome. Results of the Olivetti Heart Study. J Hypertens 2006; 24: 1633-1639.

24 Hsu PF, Chuang YS, Cheng HM, Tsai ST, Chou P, Chen CH. Clinical significance of the metabolic syndrome in the absence of established hypertension and diabetes: a community-based study. Diab Res Clin Practice 2008; 79: 461-467.

25 Eastman RD. Biochemical values in clinical medicine, 7th edn. Wright: Bristol, United Kingdom, 1985.

26 Elliott P. Observational studies of salt and blood pressure. Hypertension 1991; 17(1 suppl): 13-18. 